\title{
Heat Transfer and Flow Characteristics of Water Flow with Air Injection in Polyethylene Tube Placed over Metal Rods: Influence of Pitch Length and Tube Width
}

\author{
Takuya Kobayashi' ${ }^{1}$, Koji Toriyama ${ }^{2}$, Shumpei Funatani ${ }^{2}$ \\ ${ }^{1}$ Department of Education, Integrated Graduate School of Medicine, Engineering, and Agricultural Sciences, University of \\ Yamanashi, Yamanashi, Japan \\ ${ }^{2}$ Department of Research, Interdisciplinary Graduate School of Engineering, University of Yamanashi, Yamanashi, Japan \\ Email: g16tm006@yamanashi.ac.jp, toriyama@yamanashi.ac.jp, sfunatai@yamanashi.ac.jp
}

How to cite this paper: Kobayashi, T., Toriyama, K. and Funatani, S. (2018) Heat Transfer and Flow Characteristics of Water Flow with Air Injection in Polyethylene Tube Placed over Metal Rods: Influence of Pitch Length and Tube Width. Journal of Flow Control, Measurement \& Visualization, 6, 1-14.

https://doi.org/10.4236/jfcmv.2018.61001

Received: October 16, 2017

Accepted: December 11, 2017

Published: December 14, 2017

Copyright $(0) 2018$ by authors and Scientific Research Publishing Inc. This work is licensed under the Creative Commons Attribution International License (CC BY 4.0).

http://creativecommons.org/licenses/by/4.0/

\begin{abstract}
A polyethylene tube can be used as a heat exchanger for a low-running-cost temperature control system. In this system, the flow of temperature-controlled water in the tube is used as the heat source, and the tube is placed on the ceiling of a temperature-controlled space using a metal net. Owing to this structure, the tube is deformed by its weight. This deformation has a significant influence on heat transfer and flow characteristics. Therefore, an air injection method, in which air and water are injected simultaneously into the tube, is developed for preventing the deformation of the tube. In this study, bedding metal rods were used instead of a metal net. The influence of the pitch length of the metal rods $(5-15 \mathrm{~cm}$ ) and the width of the polyethylene tube 15, 20, 25, 30 , and $35 \mathrm{~cm}$ was examined experimentally. The length of the polyethylene tube was $178 \mathrm{~cm}$. The air flow rate was $9.5 \times 10^{-5} \mathrm{~m}^{3} / \mathrm{s}$. The water flow rates were $60,80,100,120$, and $140 \mathrm{~mL} / \mathrm{min}$. Results show that the thermal response improved because of air injection. In particular, the temperature at steady state increased, and steady state was attained approximately 1.2 - 3 times faster with air injection than without air injection. The optimum pitch length of the metal rods and the range of the optimum width of the polyethylene tube were $8 \mathrm{~cm}$ and $20-25 \mathrm{~cm}$, respectively, with and without air injection.
\end{abstract}

\section{Keywords}

Polyethylene Tube, Air Injection, Heat Transfer, Flow Characteristics, Thermal Response 


\section{Introduction}

Currently, a few vegetables and fruits are available in the market throughout the year because farmers grow crops using air conditioners and boilers in agricultural greenhouses. However, the running cost of controlling temperature using air conditioners and boilers is considerably high. According to a survey by the Ministry of Agriculture, Forestry and Fisheries in Japan, the annual heating cost of agricultural greenhouse in a farmhouse was estimated to be JPY 979,000 [1]. However, it is estimated that the running cost would be higher than this value because only a few of these greenhouses are heating throughout the year. In addition, the running cost is different depending on the applied temperature control facility. Therefore, a lot of farmers have implemented measures to reduce the running cost [2]. However, details of running costs are not easily accessible owing to reasons such as company confidentiality policy. However, according to a statement by a tomato cultivating company, the running cost of a general size agricultural greenhouse is approximately $\$ 10,000 /$ month. Moreover, the environmental influence of these temperature control systems is of concern because air conditioners use considerable electric power and boilers discharge carbon dioxide. Therefore, a temperature control system with low running cost was developed using groundwater or temperature-controlled water as a heat source [3]. This proposed system reduced the fuel cost by approximately 1/10. Figure 1 shows the structure of this system. The system consists of insulated side walls and a heat exchange panel fabricated using polyethylene tubes at the roof and floor. The temperature on the surface of the polyethylene tubes can be adjusted by the flow of temperature-controlled water in the tube. In the case of heating, air temperature near the tube surface is heated by passing heated water. Therefore, the growth room is heated based on natural convection from the floor side. On the other hand, with respect to cooling, this natural convection occurs from the roof side. As a result of this mechanism, the temperature of the growth room must be adjusted at a later time than the tube surface temperature. Therefore, to develop a system that adjusts the fruiting time, a faster response of this heat exchanger is required. Water in this system is heated using a solar collector with a heat pump (YAZAKI Co., Ltd.) and temperature adjustment (KEYENCE Co., Ltd.). A subsequent study confirmed that the temperature could be controlled in summer and winter using this system [4]. However, the polyethylene tube was deformed by the structure of this system; the tube was placed on bedding metal rod sets. The intensity of sunlight entering the growth room is not evenly reduced owing to the small diameters of the metal rods in use $(\phi=4 \mathrm{~mm})$. Figure 2 shows the polyethylene tube at the ceiling of the temperature-controlled space. This tube deformed under its weight. This deformation had a significant influence on heat transfer and flow characteristics. In terms of research on the deformed flow channel, the characteristics of a periodic combined channel were studied [5]. In this channel, the period of steady flow coincided with the period of the channel. In addition, laminar dispersion in an elliptical pipe was investi- 


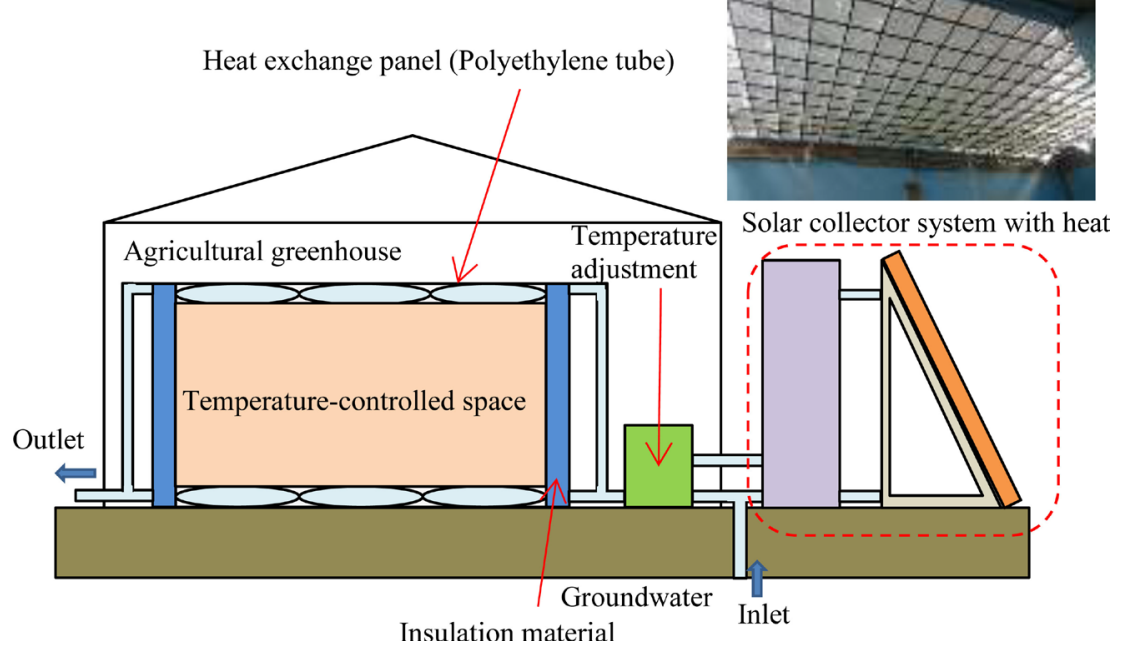

Figure 1. Structure of temperature control system.

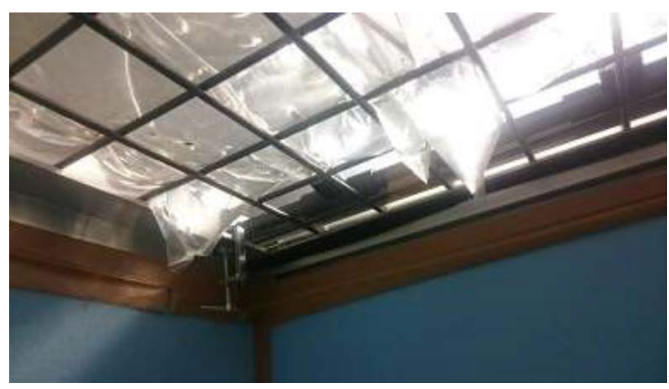

Figure 2. Heat exchange panel at roof of temperature-controlled space.

gated [6]. It was found that the dimensionless dispersion coefficient of the pipe with an elliptical cross section increased sharply as the shape ratio increased or decreased. Moreover, the numerical analysis of laminar temperature-stratified flow in a horizontal duct was studied [7]. It was observed that an extremely large vortex formed at the exit of the duct for a high Grashof number. However, several previous studies did not consider deformation. The air-injection method was developed for decreasing the influence of deformation [8]. The gas-liquid two-phase flow was formed in a polyethylene tube when water and air were injected simultaneously. Furthermore, in terms of the study on the gas-liquid two-phase flow, the flow characteristics and mass transfer in multiphase flow in a microchannel [9] were reported and an overview of recent literature on fluid flow and mass transfer behavior in multiphase flow in microchannels was provided. Moreover, it was reported that in an abruptly expanding horizontal flow passage [10], a regular oscillation phenomenon occurs in the case of shear flow, slag flow, stratified flow, and jet flow jetted into the element. However, experiments on how the flow channel deformed randomly, similar to the present polyethylene tube, have not been conducted. Thus, we experimentally examined the heat transfer and flow characteristics in a polyethylene tube with air injection, and reported that these were improved [11].

In this study, the air injection method was experimentally examined for dif- 
ferent pitch lengths of bedding metal rods and widths of the polyethylene tube. The optimum values of these parameters were evaluated using thermal response.

\section{Structure of Heat Exchange Panel}

Figure 3 shows the structure of the heat exchange panel with the proposed temperature-controlled system. This panel was constructed using polyethylene tubes, polyvinyl chloride pipes, and an aluminum frame, and its size was $180 \times$ $90 \mathrm{~cm}$. To install the panel, a metal net was attached to its bottom. Therefore, the polyethylene tube deformed under its weight. The flow in the tube and thermal response deteriorated because of this deformation.

\section{Experimental Apparatus}

The schematic of the experimental apparatus is shown in Figure 4. Compressed air was generated using a screw compressor (KOBE SEIKO Co., Ltd.) outside the

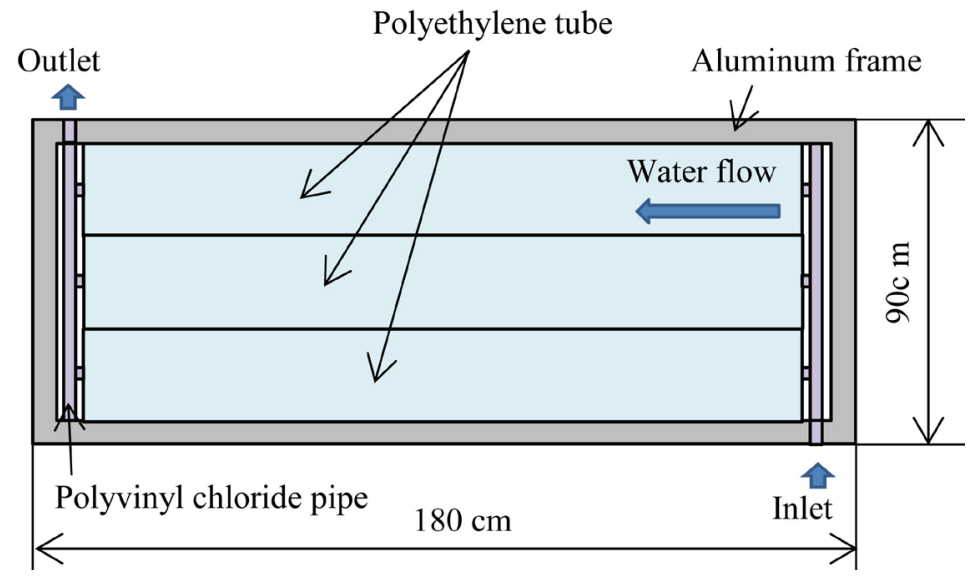

Figure 3. Structure of heat exchange panel for temperature-controlled system.

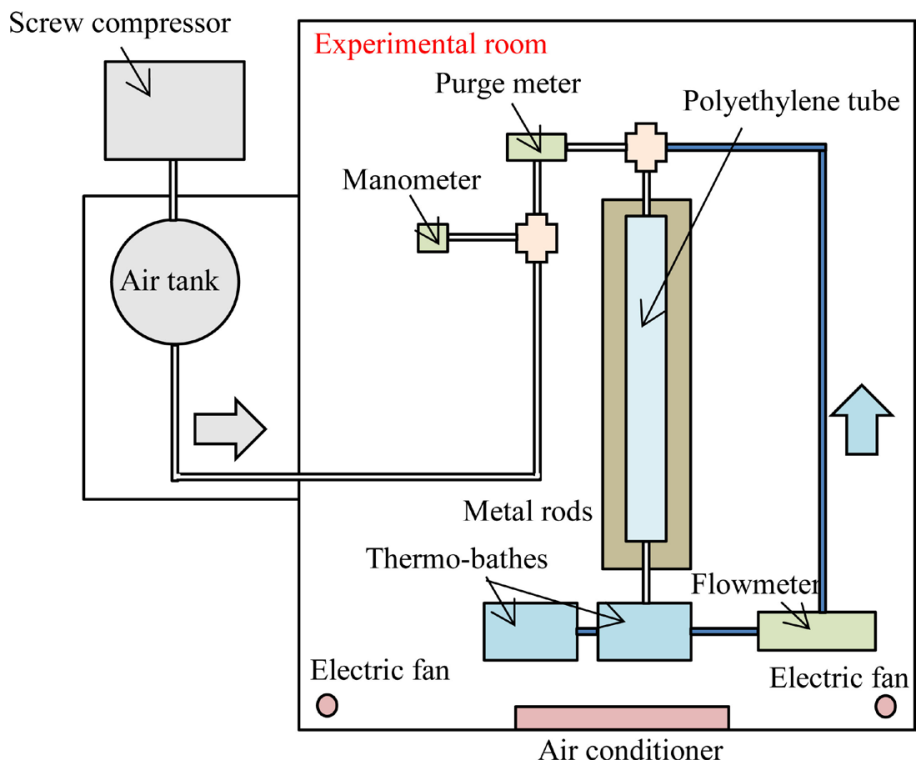

Figure 4. Experimental apparatus. 
experimental room and stored in an air tank (KOBE SEIKO Co., Ltd.) in the experimental room. The air flow rate was measured using a purge meter (TOKYO KEISOU Co., Ltd.), and it was controlled using a needle valve. The air pressure was measured using a manometer. The temperature of water flowing in the polyethylene tube was controlled using two thermobathes (YAMATO KAGAKU Co., Ltd.). The ambient temperature in the experimental room was controlled using an air conditioner and two fans.

Figure 5 shows the schematic of the test section in this system. This test section contains one polyethylene tube, in which air and water can flow simultaneously. This tube was placed over metal rod sets, and the pitch lengths of the metal rods (diameter of metal rod: $4 \mathrm{~mm}$ ) can be set as $2 \mathrm{~cm}$ or $5 \mathrm{~cm}$.

To measure the temperature distribution of the polyethylene tube along the flow direction, thermocouples were installed at the inlet and outlet of the tube and on its surface at $0,44.5,89,133.5$, and $178 \mathrm{~cm}$ at equal intervals.

\section{Experimental Conditions and Method}

In this study, experiments were conducted under the climatic conditions of spring and autumn. The experimental conditions are presented in Table 1 . The rate of air injection was $9.5 \times 10^{-5} \mathrm{~m}^{3} / \mathrm{s}$. The pitch lengths of the metal rods, $X_{P}$, were $5,6,8,10,12,14$, and $15 \mathrm{~cm}$. The measurement times when water was passed through the test section with and without air injection were approximately 1 and $3 \mathrm{~h}$, respectively.

The length of the polyethylene tube was $178 \mathrm{~cm}$ because the length of the panel was approximately $180 \mathrm{~cm}$. The widths of the polyethylene tube, $W_{P}$, were 15 , $20,25,30$, and $35 \mathrm{~cm}$. The thicknesses of the polyethylene tube were $0.1 \mathrm{~mm}\left(W_{P}\right.$ $=25,30$, and $35 \mathrm{~cm})$ and $0.06 \mathrm{~mm}\left(W_{P}=15\right.$ and $\left.20 \mathrm{~cm}\right)$. When $W_{P}$ was changed,

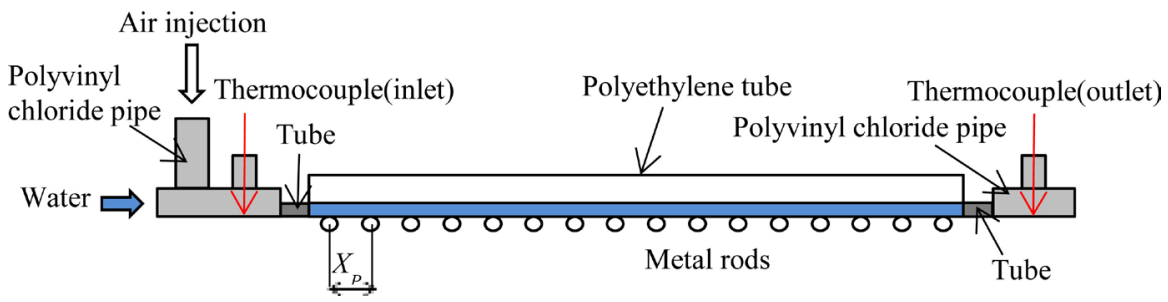

Figure 5. Structure of the test section.

Table 1. Experimental conditions (clamped conditions).

\begin{tabular}{cccc}
\hline Indices & Parameter & Value & Units \\
\hline$T r$ & Ambient temperature & 21 & ${ }^{\circ} \mathrm{C}$ \\
$T_{C}$ & Initial temperature & 21 & ${ }^{\circ} \mathrm{C}$ \\
$T_{h}$ & Inlet water temperature & 45 & ${ }^{\circ} \mathrm{C}$ \\
$Q_{A i r}$ & Air flow rate & $9.5 \times 10^{-5}$ & $\mathrm{~m}^{3} / \mathrm{s}$ \\
$X_{P}$ & Pitch length of metal rods & $5,6,8,10,12,14,15$ & $\mathrm{~cm}^{\circ}$ \\
$W_{P}$ & Width of the polyethylene tube & $15,20,25,30,35$ & ${ }^{\mathrm{cm}}$ \\
\hline
\end{tabular}


Table 2. Experimental conditions (for different $W_{P}$ ).

\begin{tabular}{lcl}
\hline$W_{P}$ & $Q_{\text {Water }}($ water flow rate $)$ & Units \\
\hline 15 & 60 & $\mathrm{~mL} / \mathrm{min}$ \\
20 & 80 & $\mathrm{~mL} / \mathrm{min}$ \\
25 & 100 & $\mathrm{~mL} / \mathrm{min}$ \\
30 & 120 & $\mathrm{~mL} / \mathrm{min}$ \\
35 & 140 & $\mathrm{~mL} / \mathrm{min}$ \\
\hline
\end{tabular}

the water flow rate $\left(Q_{\text {water }}\right)$ was changed such that the average velocity along the flow direction in the polyethylene tube remained the same. The value of $Q_{\text {Water }}$ for each $W_{P}$ is indicated in Table 2 .

In this study, the thermal flow behavior was evaluated using thermal response. The experimental procedure is described below:

1) The initial water temperature at the inlet and the ambient temperatures were set to be the same $\left(21^{\circ} \mathrm{C}\right)$. By passing water through the polyethylene tube for $15 \mathrm{~min}$, the temperature of the inlet and outlet of the polyethylene tube and that of the tube surface were set to be the same. At this time, $Q_{\text {water }}$ was 500 $\mathrm{mL} / \mathrm{min}$.

2) The flow of water through the polyethylene tube was stopped, and the water was discharged for $20 \mathrm{~min}$. Using this approach, the temperature inside the polyethylene tube and the ambient temperature were set to be the same.

3) At the start of the experiment, water at $T_{h}=45^{\circ} \mathrm{C}$ (heated by thermo-bathes) was introduced into the polyethylene tube.

The thermal response can be evaluated using this method as heated water flows from the inlet of the polyethylene tube.

\section{Evaluation Formulas}

The experimental results were evaluated with non-dimensional quantities, which are defined as follows:

Dimensionless temperature:

$$
\Theta=\frac{T-T_{C}}{T_{H}-T_{C}}
$$

Dimensionless time:

$$
\tau=\frac{\rho \times Q \times t}{m}
$$

At steady state, the relationship between the dimensionless time and dimensionless temperature is given by

$$
\Theta\left(\tau_{\max }\right)=0.95 \Theta_{\text {max }}
$$

In Equation (1), $T, T_{O}$ and $T_{H}$ denote the temperature, initial temperature, and inlet water temperature, respectively. In Equation (2), $\rho, Q, t$, and $m$ denote the density $\left[\mathrm{kg} / \mathrm{m}^{3}\right]$, flow rate $\left[\mathrm{m}^{3} / \mathrm{s}\right]$, time $[\mathrm{s}]$, and mass $[\mathrm{kg}]$ of water in the po- 
lyethylene tube as the initial condition, respectively. When the dimensionless time was 1, the mass of injected water was the same as mass of water in the polyethylene tube. In Equation (3), $\tau_{\max }$ and $\Theta_{\max }$ denote the dimensionless time and dimensionless temperature at steady state. It is important for the time to reach steady state to be short, since a faster response of the heat exchanger is required.

\section{Results and Discussion}

\subsection{Mass of Water in the Polyethylene Tube}

First, we measured the mass of water in the polyethylene tube, $m$, in Equation (2). As $m$ will not be the same each time owing to the difference in the polyethylene tube deformation, $m$ was measured 10 times for each condition of $X_{P}$, and the average value was used. The values of $m$ are shown in Figure 6, while the average and standard deviation are presented in Table 3. In the case of $X_{P}=14$ and $15 \mathrm{~cm}$, we measured the mass only once because of the possibility of breaking the polyethylene tube. The mass of water in the polyethylene tube increased linearly with $X_{P}$. For $X_{P}=8$ to $10 \mathrm{~cm}$, the standard deviations of the values of mass were stable. Based on this, it was considered that the flow condition in the polyethylene tube was stable for $X_{P}=8$ to $10 \mathrm{~cm}$.

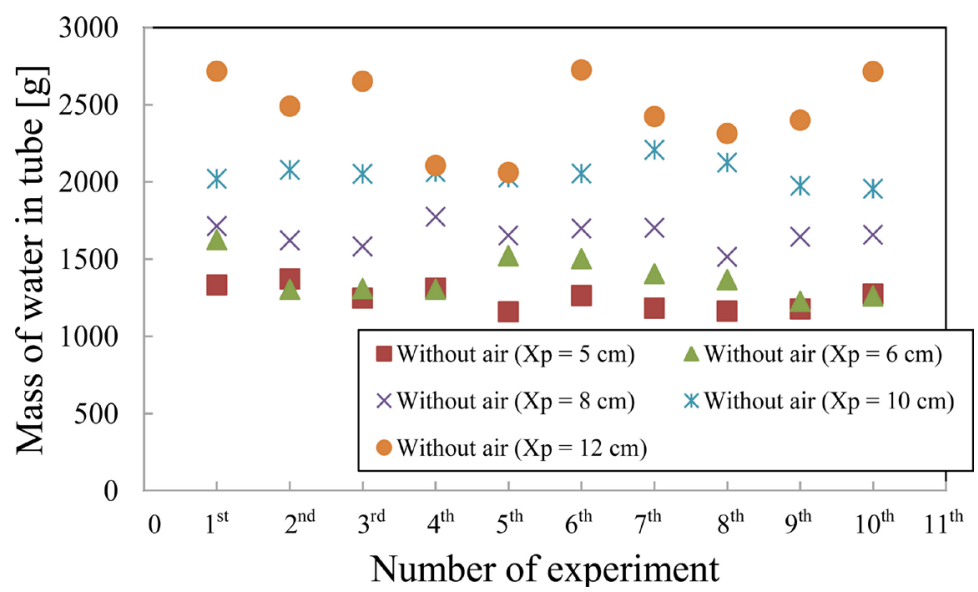

Figure 6. Mass of water in polyethylene tube.

Table 3. Average and standard deviation of mass of water in the polyethylene tube for different $X_{P}$

\begin{tabular}{ccc}
\hline$X_{P}[\mathrm{~cm}]$ & Average mass $[\mathrm{g}]$ & Standard deviation $[\mathrm{g}]$ \\
\hline 5 & 1247.3 & 71.5 \\
6 & 1381.2 & 122.9 \\
8 & 1655.0 & 69.3 \\
10 & 2054.9 & 68.7 \\
12 & 2459.1 & 234.7 \\
14 & 3429.8 & \\
15 & 4326.2 & \\
\hline
\end{tabular}




\subsection{Influence of Pitch Length}

In this experiment, the length, width, and thickness of the polyethylene tube were $178 \mathrm{~cm}, 25 \mathrm{~cm}$, and $0.1 \mathrm{~mm}$, respectively. The relationship between $\Theta_{\max }$ and $X_{P}$ is shown in Figure 7. $\Theta_{\max }$ decreased in the downstream direction for every pitch length. In addition, $\Theta_{\max }$ decreased slightly as $X_{P}$ increased. For this reason, the flow structure deteriorated when $X_{P}$ increased. Particularly, in the case of $X_{P}=10,12$, and $15 \mathrm{~cm}, \Theta_{\max }$ decreased in the downstream region from $133.5 \mathrm{~cm}$. Figure 8 shows the relationship between the time required to reach steady state and $X_{P}$. Under all conditions, the time required to reach steady state downstream of the polyethylene tube was high. However, this problem can be solved by reducing the length of the polyethylene tube. Moreover, in the upstream region, the time required to reach steady state was shortest for a pitch length of $8 \mathrm{~cm}$ for all conditions. Originally, $X_{P}=5$ and $6 \mathrm{~cm}$ were considered as optimum pitch lengths because $X_{P}$ was short. However, partial flow was observed for $X_{P}=5$ and $6 \mathrm{~cm}$. For this reason, the time required to reach steady state in the downstream region from $89 \mathrm{~cm}$ was longer than under other conditions. Furthermore, $X_{P}=10$ to $14 \mathrm{~cm}$ were considered as optimum pitch lengths

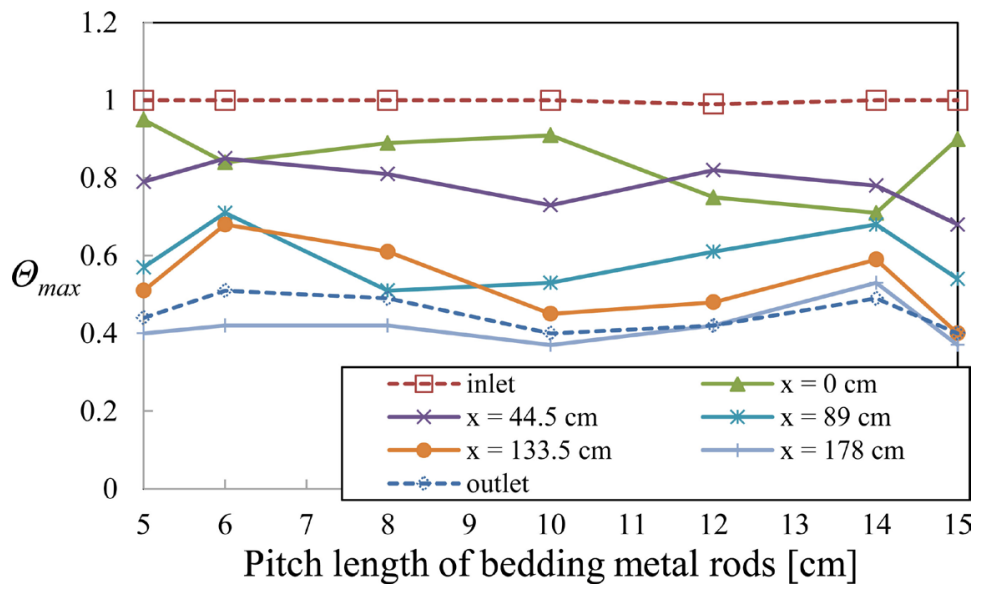

Figure 7. Relationship between $\Theta_{\max }$ and $X_{P}$.

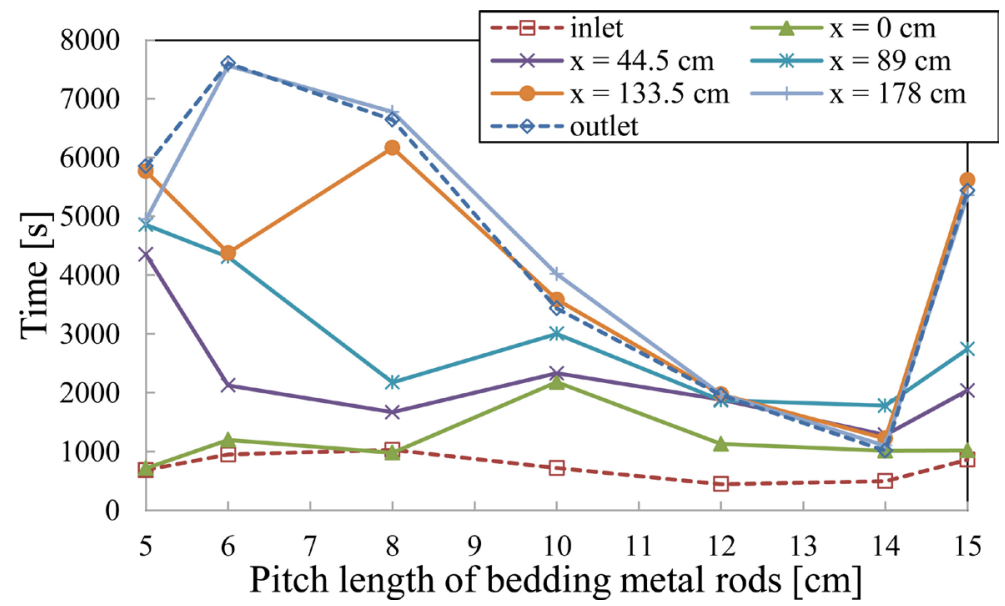

Figure 8. Relationship between time required to reach steady state and $X_{P}$. 
because the time required to reach steady state was the shortest for all conditions. However, the mass of water in the polyethylene tube was high (approximately $2000-3500 \mathrm{~g}$ ) and there was a risk of breaking the polyethylene tube when assembling the temperature control system. Therefore, the optimum pitch length was considered as $8 \mathrm{~cm}$ based on the mass of water and the stability of flow in the polyethylene tube.

\subsection{Influence of Air Injection}

The deformation of the polyethylene tube by air injection is shown in Figure 9 . Stratified flow of water and air exists inside the polyethylene tube. The deformation of the polyethylene tube can be suppressed using air injection because the tube swells. Figure 10 shows the appearance of the flow condition with and without air injection. The red arrow in the figure indicates the flow direction. In the case without air injection, water seems to be flowing in a typical wave-like pattern. Owing to this motion, a recirculation flow was formed at the bottom of the protrusion, and flow in the downstream side becomes worse. In the case with air injection, the flow condition was improved because of the reduced up and down oscillations by tube swells. Furthermore, as it is conceivable that the variation in the mass of water in the polyethylene tube will decrease, the mass was measured once with air injection. The result is presented in Table 4 . The mass of water in the polyethylene tube increased linearly with $X_{P}$; this is the same trend that was observed without air injection. However, the mass was the same for $X_{P}$ $=6$ to $8 \mathrm{~cm}$. For this reason, there was less deformation of the polyethylene tube for $X_{P}=8 \mathrm{~cm}$. The mass of water decreased by $6.2 \%-26.1 \%$ because of air injection. Figure 11 shows the relationship between $\Theta_{\max }$ and $X_{P}$ with air injection. $\Theta_{\max }$ was not affected by air injection because it is almost the same for all condi-
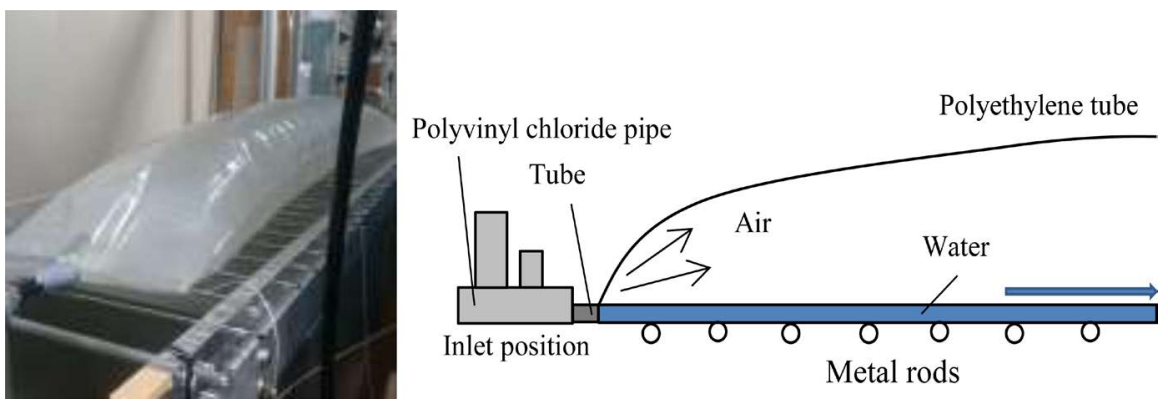

Figure 9. Appearance of the polyethylene tube with air injection (L: image; R: diagram).
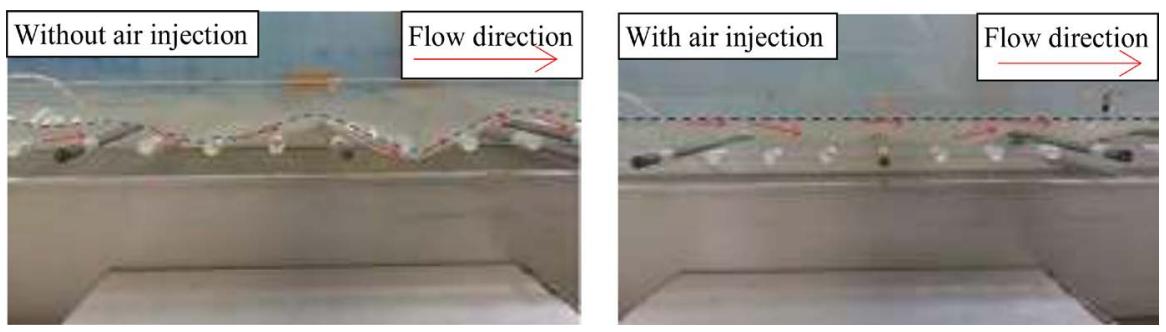

Figure 10. Appearance of flow condition (L: without air injection; R: with air injection). 
tions. Moreover, $\Theta_{\max }$ exhibited a slight rise downstream of the polyethylene tube owing to air injection. Figure 12 shows the relationship between the time required to reach steady state and $X_{P}$ with air injection. It can be observed that the times required to reach steady state upstream and downstream of the polyethylene tube with air injection were shorter than those without air injection. In the case of $X_{P}=8 \mathrm{~cm}$, the times required to reach steady state were as follows:

For instance, the time required to reach steady state at $178 \mathrm{~cm}$ :

without air injection: $t=6645 \mathrm{~s}$;

with air injection: $t=2116 \mathrm{~s}$;

ratio $=2116 \mathrm{~s} / 6645 \mathrm{~s}=0.3$.

Therefore, the time required to reach steady state with air injection was approximately 1.2 - 3 times shorter than without air injection for $X_{P}=8 \mathrm{~cm}$. Figure 13 shows the time required to reach steady state under all conditions for various pitch lengths. In all cases, the time required to reach steady state with air injection was shorter than without air injection. Therefore, sufficient effect can be obtained through air injection. The optimum pitch length was $5 \mathrm{~cm}$ with air injection and $8 \mathrm{~cm}$ without air injection.

\subsection{Influence of Width of Polyethylene Tube}

To evaluate the effect of the width of the polyethylene tube, the case of $X_{P}=8 \mathrm{~cm}$

Table 4. Mass of water in polyethylene tube with air injection.

\begin{tabular}{ccc}
\hline$X_{P}[\mathrm{~cm}]$ & Mass of water in polyethylene tube $[\mathrm{g}]$ & Rate of decrease [\%] \\
\hline 5 & 1021.2 & 18.1 \\
6 & 1296.1 & 6.2 \\
8 & 1242.5 & 24.9 \\
10 & 1835.5 & 10.7 \\
12 & 2094.1 & 14.8 \\
14 & 2848.9 & 16.9 \\
15 & 3197.7 & 26.1 \\
\hline
\end{tabular}

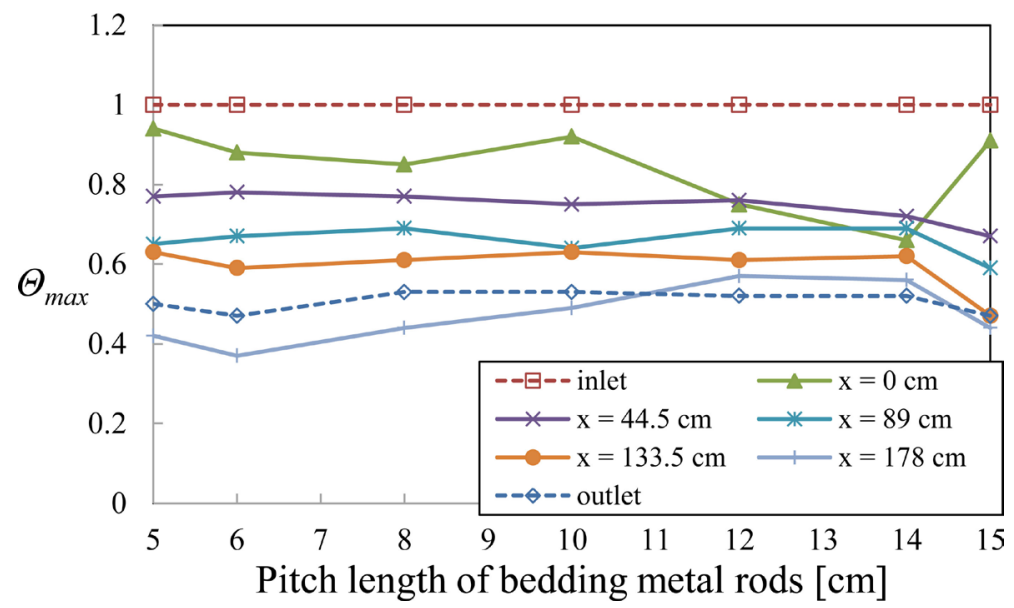

Figure 11. Relationship between $\Theta_{\max }$ and $X_{P}$ with air injection. 


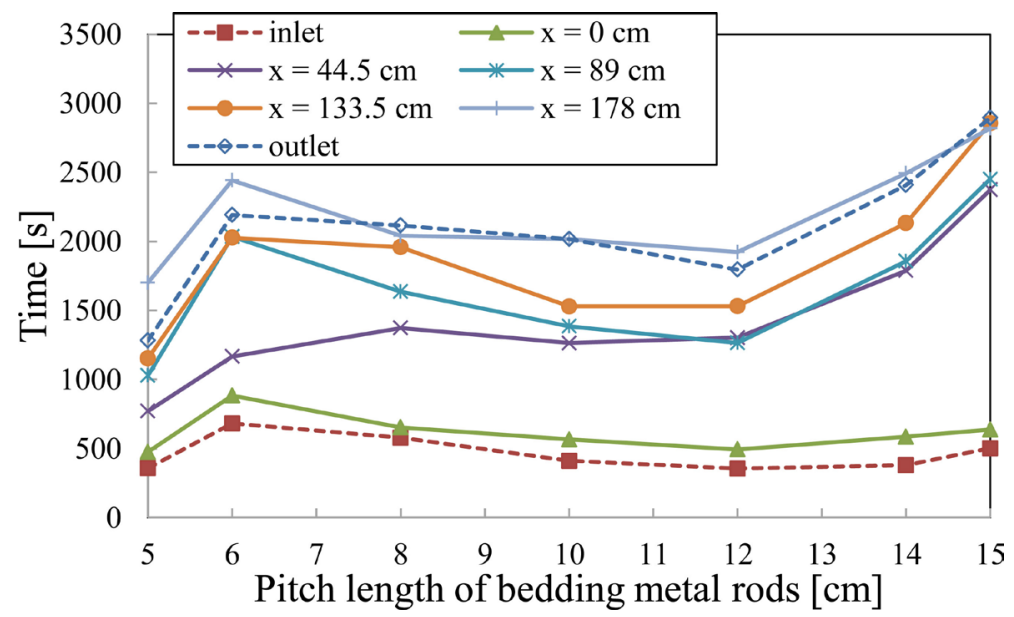

Figure 12. Relationship between time required to reach steady state and $X_{P}$ with air injection.

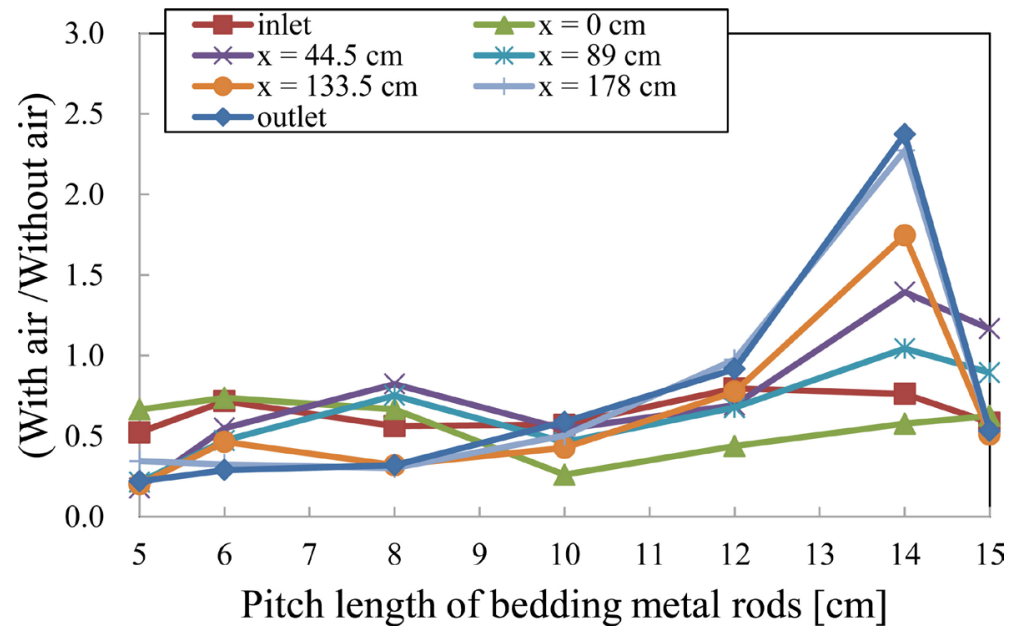

Figure 13. Comparison of time required to reach steady state in all conditions with and without air injection.

Table 5. Mass of water in polyethylene tube with air injection (for different $W_{P}$ ).

\begin{tabular}{cc}
\hline$W_{P}[\mathrm{~cm}]$ & Measured value $[\mathrm{g}]$ \\
\hline 15 & 884.6 \\
20 & 1659.8 \\
25 & 1242.5 \\
30 & 2359.0 \\
35 & 3028.4
\end{tabular}

with air injection was examined. Table 5 presents the mass of water in the polyethylene tube for various tube widths. The mass of water was measured once with air injection. Figure 14 shows the relationship between $\Theta_{\max }$ and $W_{P}$ with air injection. The dimensionless temperature at steady state was almost the same for $W_{P}=15,20$, and $25 \mathrm{~cm}$. However, it decreased for $W_{P}=30$ to $35 \mathrm{~cm}$. For this reason, the area of the cross section of the polyethylene tube was expanded. As a 


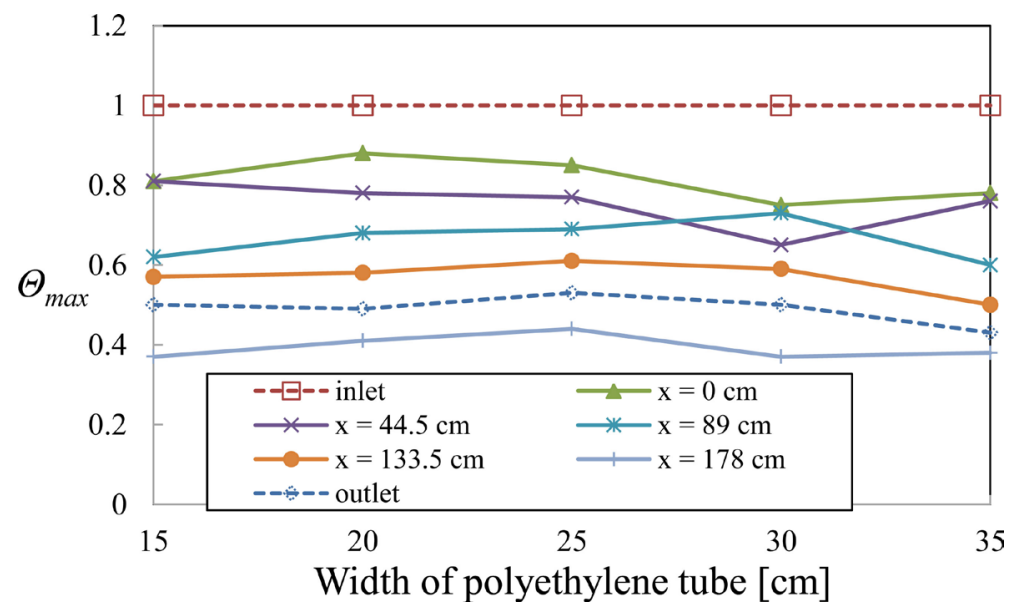

Figure 14. Relationship between $\Theta_{\max }$ and $W_{P}$ with air injection.

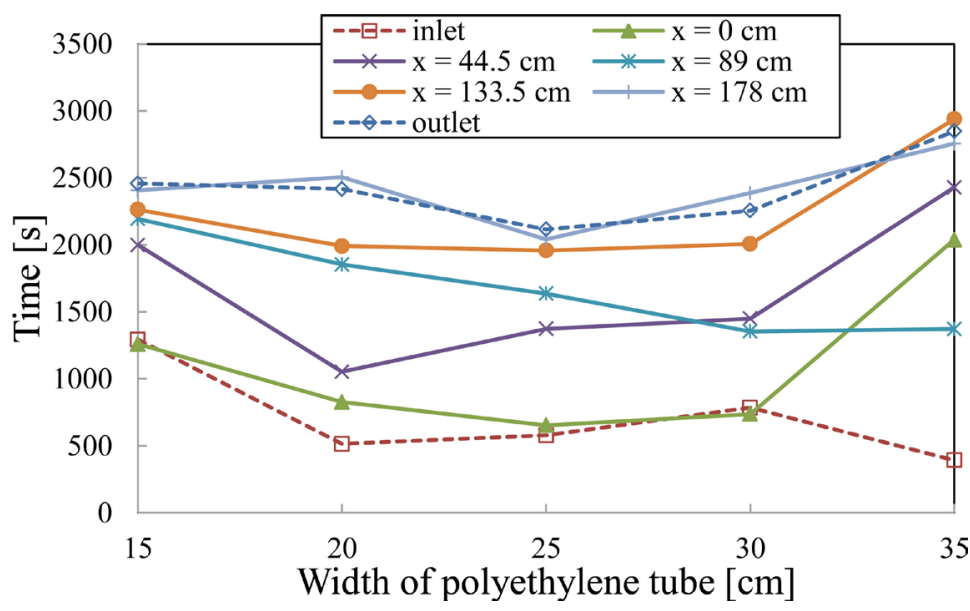

Figure 15. Relationship between time required to reach steady state and $W_{P}$ with air injection.

result, $\Theta_{\max }$ decreased because the heat transfer area increased. Figure 15 shows the relationship between the time required to reach steady state and $W_{P}$ with air injection. In the case of $W_{P}=35 \mathrm{~cm}$, the time required to reach steady state was the longest because the mass of water in the polyethylene tube was the highest. The case of $W_{P}=15 \mathrm{~cm}$ was the optimum condition. However, considering productization, a large amount of the polyethylene tube will be required and product cost will increase. As a result, $W_{P}$ in the range $20-25 \mathrm{~cm}$ was the optimum width of the polyethylene tube.

\section{Conclusions}

In this study, the thermal response and time required to reach steady state were evaluated for a polyethylene tube with various pitch lengths and widths with and without air injection. The conclusions from the study are summarized below:

1) The mass of water in the polyethylene tube increased linearly with $X_{p}$. The standard deviation of the mass of water at steady state for $X_{P}=8$ to $10 \mathrm{~cm}$ was the smallest. 
2) The optimum pitch length of the metal rods was $X_{P}=8 \mathrm{~cm}$ with and without air injection.

3) The thermal response improved because of air injection. The time required to reach steady state with air injection was 1.2 - 3 times shorter than without air injection. Furthermore, the mass of water in the polyethylene tube decreased by $6.2 \%-26.1 \%$ because of air injection. The optimum widths of the polyethylene tube were $W_{P}=20$ to $25 \mathrm{~cm}$.

\section{References}

[1] Ministry of Agriculture, Forestry and Fishers (2017) Survey on Agricultural Management. http://www.e-stat.go.jp/SG1/estat/List.do?lid=000001184284

[2] Ministry of Agriculture, Forestry and Fishers (2013) Aiming for Energy-saving Facilities Gardening.

[3] Toriyama, K., Kawai, M., Kado, T. and Funatani, S. (2015) A study of Temperature Control System by Using Groundwater in Agricultural Greenhouse. Proceedings of the Japanese Joint Conference on Air-conditioning and Refrigeration, Tokyo, 15 April 2015, 5.

[4] Toriyama, K., Kawai, M., Kobayashi, T., Nganga, J.N. and Funatani, S. (2015) Evaluation of the Cooling Performance of Temperature Control System for Agricultural Greenhouse by Passing Water Type Heat Exchange Panel. Thermal Engineering Conference, Osaka, 24-25 October 2015, CD-ROM. (in Japanese)

[5] Adachii, T., Goshi, Y. and Uehara, H. (2002) Transitions and Pressure Drop Characteristics of Flow in Periodically Combined Channels. Transactions of the Japan Society of Mechanical Engineers Series B, 68, 2232-2239. (in Japanese) https://doi.org/10.1299/kikaib.68.2232

[6] Fukusima, Y. and Hayakawa, N. (1983) Laminar Dispersion in an Elliptical Pipe and in a Rectangular Pipe. Journal of Japan Society of Fluid Mechanics, 2, 34-42.

[7] Yu, B. and Ozoe, H. (2000) Numerical Analysis of Laminar Temperature-Stratified Flow in a Horizontal Duct. The Reports of Institute of Advanced Material Study, Kyushu University, 14, 111-117.

[8] Toriyama, K., Funatani, S. and Kobayashi, T. (2016) Flow Stability System in the Duct, Agriculture Greenhouse with this System and the Methods in the Duct. Japanese Patent Application, No.2017-158476.

http://www.conceptsengine.com/patent/application/2017158476

[9] Sotowa, K. (2014) Fluid Behavior and Mass Transport Characteristics of Gas-Liquid and Liquid-Liquid Flows in Microchannels. Journal of Chemical Engineering of Japan, 47, 213-224. https://doi.org/10.1252/jcej.13we141

[10] Shakuochi, T. (1994) A Study on Gas-Liquid Two-Phase Jet Flow Introduced into an Abruptly Expanded Horizontal Flow Passage: Oscillatory Phenomena and the Application to Flow Measurement. Transactions of the Japan Society of Mechanical Engineers Series B, 60, 3359-3365. https://doi.org/10.1299/kikaib.60.3359

[11] Kobayashi, T., Toriyama, K., Nganga, J.N. and Funatani, S. (2016) Effect of Air Flow Rate on Heat and Flow Characteristics of Water in Polyethylene Tube Placed over Metal Rods Sets. The 27 th International Symposium on Transport Phenomena, Honolulu, Hawaii, 20-23 September 2016, CD-ROM. 


\section{Nomenclature}

$m:$ Mass of water in the polyethylene tube $[\mathrm{g}]$

$Q_{A i r}$ : Air flow rate $\left[\mathrm{m}^{3} / \mathrm{s}\right]$

$Q_{\text {Water }}:$ Water flow rate $[\mathrm{mL} / \mathrm{min}]$

$t$. Time [s]

T: Temperature $\left[{ }^{\circ} \mathrm{C}\right]$

$T_{C}$ Initial temperature $\left[{ }^{\circ} \mathrm{C}\right]$

$T_{h}$ : Inlet water temperature $\left[{ }^{\circ} \mathrm{C}\right]$

$T_{H}$ : Inlet water temperature $\left[{ }^{\circ} \mathrm{C}\right]$

Tr. Ambient temperature $\left[{ }^{\circ} \mathrm{C}\right]$

$X_{p}$ : Pitch length of metal rods $[\mathrm{cm}]$

$W_{P}$ : Width of polyethylene tube $[\mathrm{cm}]$

$\Theta$ : Non-dimensional temperature

$\Theta_{\max }:$ Dimensionless temperature at steady state

$\rho$ : Density of water $\left[\mathrm{kg} / \mathrm{m}^{3}\right]$

$\tau$. Dimensionless time 